\title{
Evaluation of a Lung Nodule in the Setting of Metastatic Gastrointestinal Stromal Tumor: Surgical Considerations in Carney's Triad
}

\author{
Dathe Benissan-Messan ${ }^{1}$, Emily Singer ${ }^{1}$, Peter Kneuertz ${ }^{2}$, Robert Merritt $^{3}$, Desmond D'Souza ${ }^{3}$ \\ 1. Gastrointestinal and General Surgery, The Ohio State University Wexner Medical Center, Columbus, USA 2. Thoracic \\ Surgery, The Ohio State University Wexner Medical Center, Columbus, USA 3. Surgery, The Ohio State University \\ Wexner Medical Center, Columbus, USA
}

Corresponding author: Dathe Benissan-Messan, benimess@gmail.com

\begin{abstract}
In 1977, Carney et al. first described an association of gastric epithelioid leiomyosarcoma or gastrointestinal stromal tumor (GIST), pulmonary chondroma, and extra-adrenal paraganglioma. This previously unrecognized disorder came to be known as Carney's triad. We describe a case of a 27-year-old female with metastatic GIST, diagnosed with Carney's triad following pulmonary wedge resection, and highlight the surgical implication of this rare disease association.
\end{abstract}

Categories: Cardiac/Thoracic/Vascular Surgery, Genetics, Pathology

Keywords: cancer, chest, genetic syndromes, lung, benign or congenital lesions, metastases/metastasectomy

\section{Introduction}

Carney triad is a rare syndrome characterized by the association of gastrointestinal stromal tumor (GIST), paraganglioma, and pulmonary chondroma. The etiology of the disorder is unknown. Diagnosis relies on a high index of suspicion from the clinician and management is surgical.

\section{Case Presentation}

A 27-year-old female presented with a history of abdominal pain. CT imaging of the abdomen revealed multiple gastric masses, hepatic lesions, bilateral adrenal adenomas, and a well-circumscribed pulmonary mass in the right lower lobe. Positron emission tomography revealed hypermetabolic activity in stomach, adrenal gland, retroperitoneal nodes, and in the right lung. CT-guided percutaneous lymph node biopsy of the gastric mass revealed a GIST ( $<5$ mitoses/50 HPF, CD117 positive, negative for CD34, smooth muscle actin [SMA], cytokeratin, S100. Ki-67 4\%). The patient was diagnosed with metastatic GIST and started on a highly selective tyrosine kinase inhibitor.

Received 03/09/2020

Review began 03/31/2020 Review ended 04/05/2020 Published 04/10/2020

(c) Copyright 2020

Benissan-Messan et al. This is an open access article distributed under the terms of the Creative Commons Attribution License CC-BY 4.0., which permits unrestricted use, distribution, and reproduction in any medium, provided the original author and source are credited.
The patient's disease status remained stable for three years when she developed enlargement of one of her gastric masses. Upper endoscopy evaluation revealed an ulcerated bleeding gastric mass and evidence of gastric outlet obstruction. She underwent a distal gastrectomy with Billroth II reconstruction. Pathology was consistent with a GIST. The patient then developed progressive enlargement of her right lower lobe mass two years following gastrectomy. CT chest at time of evaluation revealed a $4.9 \times 4.2 \mathrm{~cm}$ right lower lobe cystic lesion (Figure 1). 


\section{Cureus}

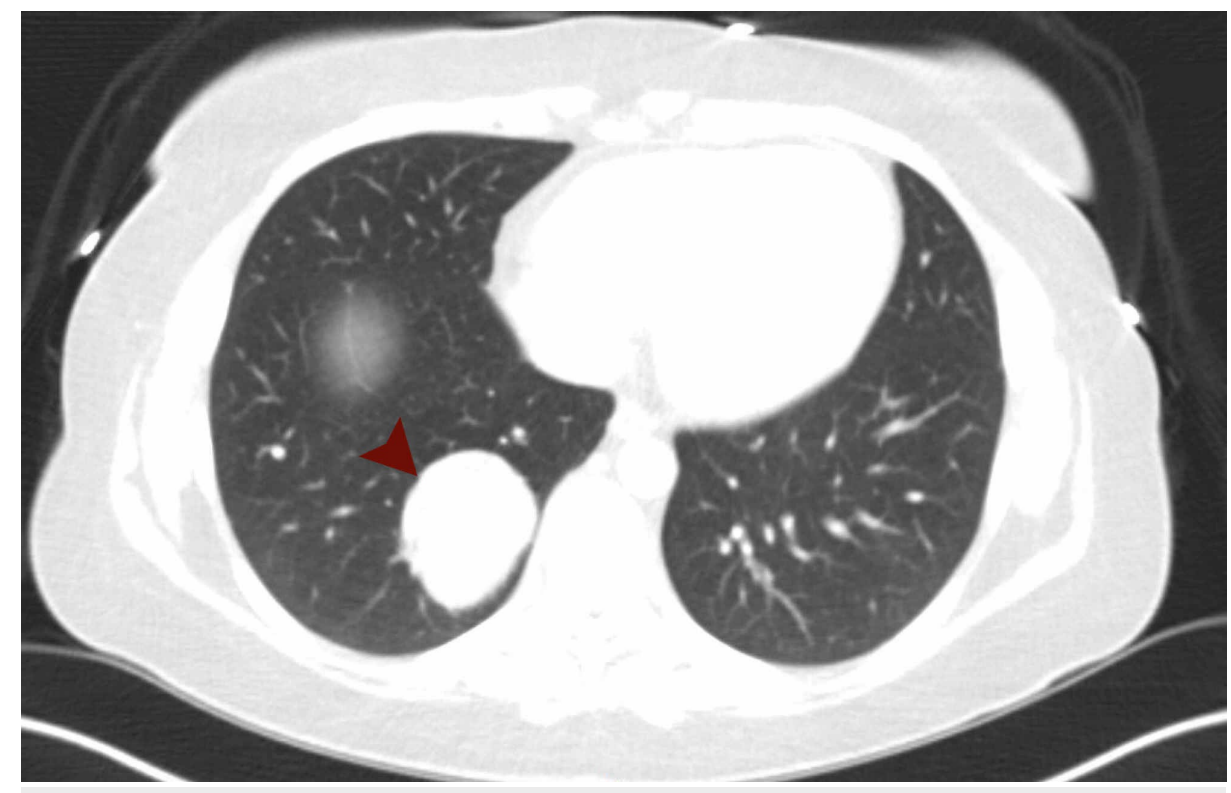

FIGURE 1: Pulmonary mass (red arrow indicates mass).

Following appropriate preoperative evaluation, she underwent an uncomplicated robotic-assisted right lower lobe wedge resection with negative margins. Pathology demonstrated a pulmonary chondroma with three reactive level 9R lymph nodes (Figures 2, 3). A diagnosis of Carney's triad was made, and she remains on maintenance tyrosine kinase inhibitor with non-progressive disease.

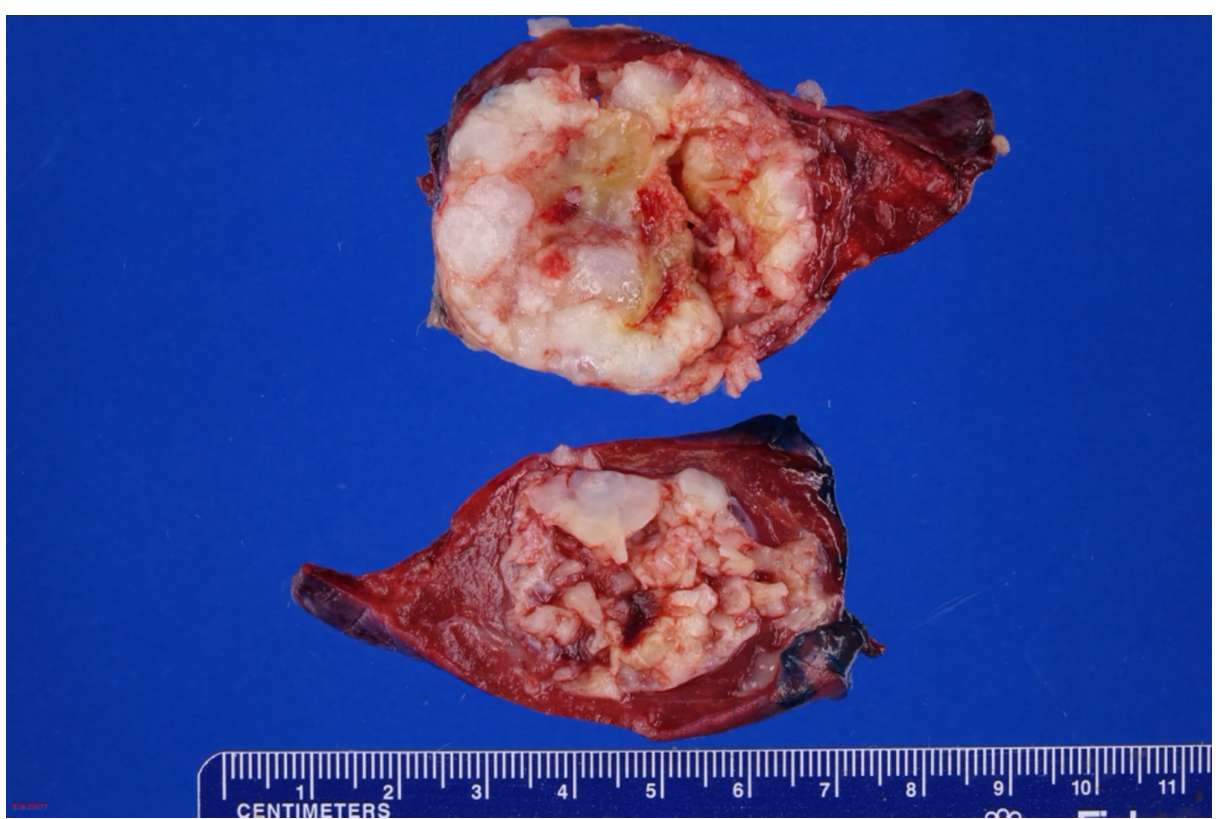

FIGURE 2: Gross features of bisected pulmonary chondroma: wellcircumscribed $4.9 \mathrm{~cm}$ lesion composed of varying in size cartilaginous lobules; there is central area of cystic degeneration. 


\section{Cureus}

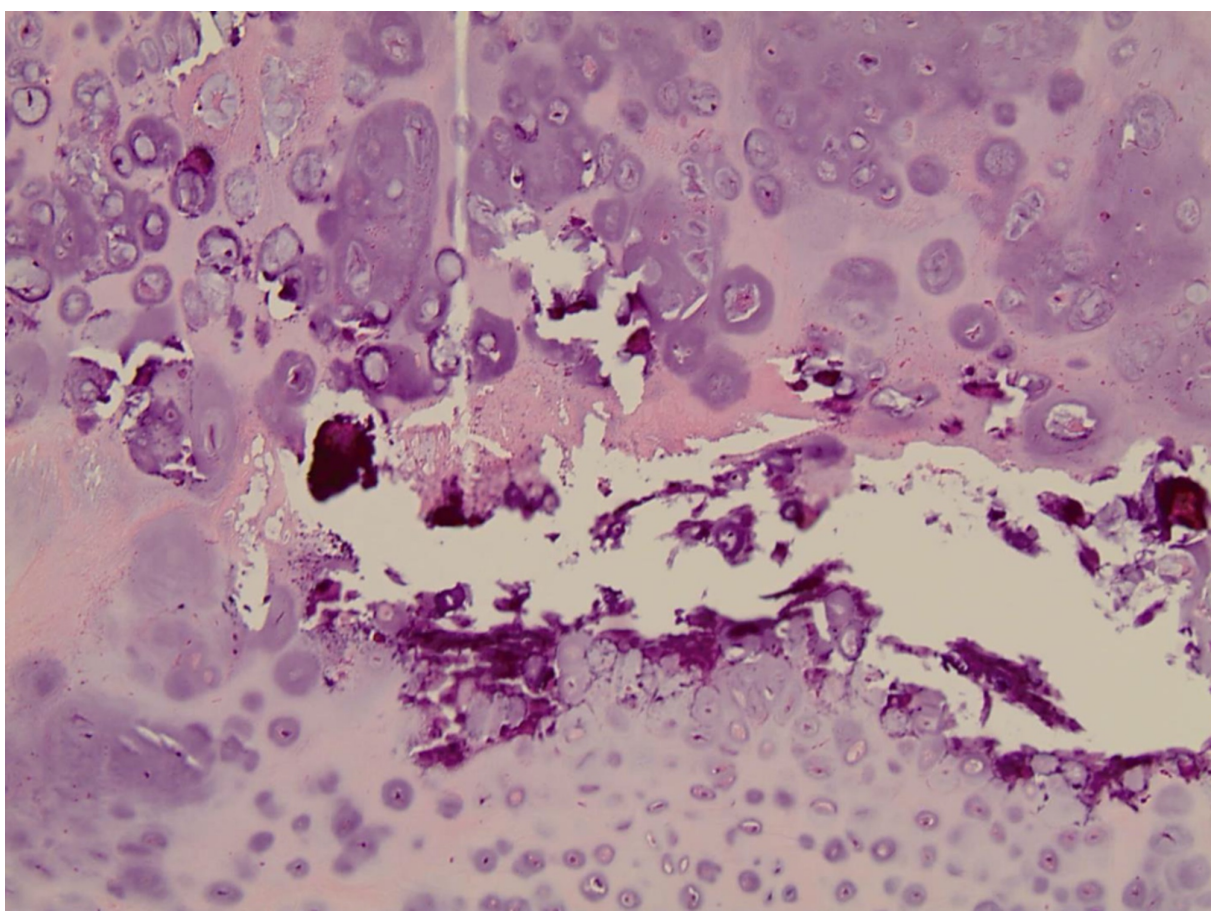

FIGURE 3: Histologic features of pulmonary chondroma: the entire lesion is composed of mature cartilage with mild cellular pleomorphism; there are foci of microscopic calcification but no other tissues and no entrapment of pulmonary parenchyma (hematoxylin and eosin stain, $\mathbf{x 2 0 0}$ original magnification).

\section{Discussion}

The disorder of synchronous or metachronous gastric GIST, pulmonary chondroma, and extra-adrenal paraganglioma was first described by Carney et al. in 1977, and thereafter came to be known as the Carney's triad [1]. Few patients have all three tumors (22\%), and therefore the presence of just two of the three tumors is considered a sufficient diagnostic criterion [2].

GIST is the most commonly observed (99\%) tumor in the triad, and gastrointestinal bleed or abdominal pain is often the presenting symptom [2]. GISTs most frequently harbor mutations in the proto-oncogene KIT (75\%-80\% of cases) [3]. This allows for treatment with selective tyrosine kinase inhibitor targeting KIT as in this case. Surgical resection remains the only curative treatment modality; however, recurrence after resection is common, occurring in $46 \%$ of patients within 1-36 years after surgery [4]. The stomach is the most common site of occurrence of GIST followed by the small bowel, rectum, and esophagus with up to $50 \%$ of patients presenting with metastasis at the time of diagnosis. Metastatic disease is treated with a combination of medical and surgical therapies. The liver and peritoneum are the two most common sites of extra-intestinal metastasis [5]. Metastatic disease to the lung and adrenal has been reported but are uncommon and should prompt further evaluation to rule out Carney's triad [6].

Pulmonary chondromas are rare benign lung tumors, present in $76 \%$ of cases of Carney's triad, and GIST plus pulmonary chondroma was the most common combination of tumors $(53 \%)[7,8]$. The pulmonary tumors are well-differentiated benign cartilaginous lesions that exhibit calcifications (Figures 2, 3). Lymph node pathology shows reactive hyperplasia, as in the present case. These tumors are characteristically asymptomatic and identified radiographically or histologically. They can be single, multiple, and bilateral, without predilection for a specific lobe and can be identified on chest X-ray, enhanced CT scan of the chest, or MRI. On CT scan, they present as round or oval nodules, often measuring between 1.0 and $4.0 \mathrm{~cm}$ with mild lobulation, of moderate soft tissue density, inhomogeneous density, with calcification and clear boundaries [8]. The pulmonary lesions can be treated with surgical resection with thoracotomy or through minimally invasive thoracoscopic or robotic approaches [9]. The lesions can also be observed over time without excision; however, the probability of developing symptoms and malignant transformation increases with tumor size [8]. In the case of suspected metastatic GIST tumor with lung tumor, pulmonary wedge resections are helpful in establishing the diagnosis of Carney's triad in some cases.

Extra-adrenal gangliomas were present in $47 \%$ of Carney's case series [4,7]. The common locations included carotid body, sympathetic chain, retroperitoneum, and adrenal glands [2]. In a retrospective review, these 
lesions were characteristically multifocal (22\%); $16 \%$ were functional pheochromocytoma and $13 \%$ were non-functioning adrenocortical tumors [4]. Elevated plasma levels of catecholamines are found in cases of functioning paraganglioma [2]. Surgical resection was curative in most cases (90\%), and inoperable tumors were treated with phenoxybenzamine hydrochloride, chemotherapy, radiation, or polyvinyl alcohol particle embolization [4].

\section{Conclusions}

Each of the characteristic tumors in Carney's triad is rare; however patients who develop these lesions in clusters should undergo thorough and ongoing surveillance, particularly if the patient is female, younger than 40 years, and has multifocal tumors. Surgical resection remains the mainstay of therapy and has curative potential. Long tumor-free intervals have been reported prior to recurrence or development of new sites of disease. Lifelong surveillance is recommended. Carney's triad should be considered in a patient with metastatic GIST and lung tumor.

\section{Additional Information \\ Disclosures}

Human subjects: Consent was obtained by all participants in this study. Conflicts of interest: In compliance with the ICMJE uniform disclosure form, all authors declare the following: Payment/services info: All authors have declared that no financial support was received from any organization for the submitted work. Financial relationships: All authors have declared that they have no financial relationships at present or within the previous three years with any organizations that might have an interest in the submitted work. Other relationships: Dr. Merritt, a speaker, reports personal fees from Intuitive Surgical, during the conduct of the study. Dr. D’Souza, a proctor, reports personal fees from Intuitive Surgical, outside the submitted work. .

\section{Acknowledgements}

We acknowledge Konstantin Shilo, MD and Chen Wei, MD for providing the pathological slides and specimen images.

\section{References}

1. Carney JA, Sheps SG, Go VL, Gordon H: The triad of gastric leiomyosarcoma, functioning extra-adrenal paraganglioma and pulmonary chondroma. N Engl J Med. 1977, 296:1517-1518. 10.1056/nejm197706302962609

2. de Jong E, Mulder W, Nooitgedacht E, Taat CW, Bras J: Carney's triad. Eur J Surg Oncol. 1998, 24:147-149. 10.1016/s0748-7983(98)91693-6

3. Mei L, Smith SC, Faber AC, et al.: Gastrointestinal stromal tumors: the GIST of precision medicine. Trends Cancer. 2018, 4:74-91. 10.1016/j.trecan.2017.11.006

4. Carney JA: Gastric stromal sarcoma, pulmonary chondroma, and extra-adrenal paraganglioma (Carney triad): natural history, adrenocortical component, and possible familial occurrence. Mayo Clin Proc. 1999, 74:543-552. 10.4065/74.6.543

5. Bamboat ZM, Dematteo RP: Updates on the management of gastrointestinal stromal tumors . Surg Oncol Clin N Am. 2012, 21:301-316. 10.1016/j.soc.2011.12.004

6. Ozan E, Oztekin O, Alacacioglu A, Aykas A, Postaci H, Adibelli Z: Esophageal gastrointestinal stromal tumor with pulmonary and bone metastases. Diagn Interv Radiol. 2010, 16:217-220. 10.4261/1305-3825.Dir.186108.2

7. Byrne CM, Daneshjoo R, Ma-Wyatt J, Cox M: Gastrointestinal haemorrhage as a presentation of Carney's triad. ANZ J Surg. 2007, 77:88-90. 10.1111/j.1445-2197.2006.03892.x

8. Tian D, Wen H, Zhou Y, Fu M: Pulmonary chondroma: a clinicopathological study of 29 cases and a review of the literature. Mol Clin Oncol. 2016, 5:211-215. 10.3892/mco.2016.945

9. Ludwig C, Zeitoun M, Stoelben E: Video-assisted thoracoscopic resection of pulmonary lesions. Eur J Surg Oncol. 2004, 30:1118-1122. 10.1016/j.ejso.2004.07.005 